\title{
Vacuolar processing enzymes, AmVPE1 and AmVPE2, as potential executors of ethylene regulated programmed cell death in the lace plant (Aponogeton madagascariensis)
}

\begin{tabular}{|r|l|}
\hline Journal: & Botany \\
\hline Manuscript ID & cjb-2017-0184.R1 \\
\hline Manuscript Type: & Article \\
\hline Date Submitted by the Author: & $19-$ Nov-2017 \\
\hline $\begin{array}{r}\text { Complete List of Authors: } \\
\text { Is the invited manuscript for } \\
\text { consideration in a Special } \\
\text { Issue? : }\end{array}$ & $\begin{array}{l}\text { Rantong, Gaolathe; Dalhousie University, Biology; Botswana International } \\
\text { Biotechnological Sciences } \\
\text { Gunawardena, Arunika; Dalhousie University, }\end{array}$ \\
\hline Keyword: & $\begin{array}{l}\text { lace plant, vacuolar processing enzymes, ethylene, perforations, leaf } \\
\text { development }\end{array}$ \\
\hline
\end{tabular}

\section{SCHOLARONE \\ Manuscripts}


Vacuolar processing enzymes, AmVPE1 and AmVPE2, as potential executors of ethylene regulated programmed cell death in the lace plant (Aponogeton madagascariensis)

Gaolathe Rantong\$ and Arunika H.L.A.N. Gunawardena*

Department of Biology, Dalhousie University, 1355 Oxford Street, Life Sciences Centre, Halifax, NS, B3H 4R2, Canada

g1997755@dal.ca (G. Rantong) arunika.gunawardena@dal.ca (A. H.L.A.N. Gunawardena)

Running title: Role of vacuolar processing enzymes in lace PCD

$\$$ Current address: Botswana International University of Science and Technology, Department of Biological and Biotechnological Sciences, College of Sciences, Private Bag 16, Palapye, Botswana

* Corresponding author: Arunika Gunawardena (email: arunika.gunawardena@dal.ca, Phone: +1 902494 1594) 


\section{Summary}

Perforation formation in Aponogeton madagascariensis (lace plant) is an excellent model for studying developmentally regulated programmed cell death (PCD). In this study, we isolated and identified two lace plant vacuolar processing enzymes (VPEs) and investigated their involvement during PCD and throughout leaf development. Lace plant VPE transcript levels were determined during seven different stages of leaf development. PCD and non-PCD cells from "window" stage leaves (in which perforations are forming) were separated through laser-capture microscopy and their transcript levels were also determined. VPE activity was also studied between the cell types, through a VPE activity-based probe JOPD1. Additionally, VPE transcript levels were studied in plants treated with an ethylene biosynthesis inhibitor, aminoethoxyvinylglycine (AVG). The two isolated VPEs, $A m$ VPE1 and $A m$ VPE2, are vegetative type VPEs. AmVPE1 had higher transcript levels during a preperforation developmental stage, immediately prior to visible signs of PCD. AmVPE2 transcripts were higher later during window and late window stages. Both VPEs had higher transcript and activity levels in PCD compared to non-PCD cells. AVG treatment inhibited PCD and associated increases in VPE transcript levels. Our results suggested that VPEs are involved in the execution of the ethylene related PCD in the lace plant.

Keywords: Aponogeton madagascariensis, ethylene, leaf development, perforation formation, programmed cell death, vacuolar processing enzymes 


\section{Introduction}

Programmed cell death (PCD) is regulated cell demise necessary for elimination of specific cells in most multicellular organisms, development, adaptation and response to stress (Greenberg 1996; Lam 2004). It has been observed in unicellular and multicellular organisms, including fungi, plants and animals (Rantong and Gunawardena 2015). In mammals, apoptosis (a form of PCD) is modulated and executed by caspases. Although the execution of PCD through caspases is well understood in animals, execution of PCD in plants is still unclear. In addition, plant species whose complete genomes have been sequenced lack genes encoding true caspases. However, some of the hallmarks of animal PCD, which are directly or indirectly effects of caspases, are also observed in plants. These include chromatin condensation, DNA laddering, release of cytochrome c, shrinkage of the cytoplasm, and activation of death proteases (Wang et al. 1996; Adrain and Martin 2001; reviewed in Elmore 2007; reviewed in Reape and McCabe 2008). This suggests the presence of proteins that perform caspase-like duties during plant PCD. Identification of such proteins led to the isolation of saspases (Dodson and Wlodawer 1998; Coffeen and Wolper 2004), phytaspases (Chichkova et al. 2010; Cai and Gallois 2015), metacaspases (Uren et al. 2000), and vacuolar processing enzymes (VPEs;Kinoshita et al. 1995a, b; reviewed in Bonneau et al. 2008; Cai and Gallois 2015).

VPEs share many characteristics with animal caspases. They are both cysteine proteases, have a His-Cys catalytic dyad, are synthesized as inactive proenzymes, can cleave after Asp residues in similar synthetic substrates and share similar inhibitors (Hatsugai et al. 2004; Rojo et al. 2004; Misas-Villamil et al. 2013). VPEs are more similar to caspase-1 in terms of their catalytic dyad, inhibitors and substrates (Wilson et al. 1994; Cohen 1997; Hiraiwa et al. 1999; Nicholson, 1999; Hara-Nishimura et al. 2005; Sanmartin et al. 2005). Due to the similarities with caspases, VPEs have been isolated in several species and their role in plant PCD is under investigation. In tobacco, caspase-1 activity required for PCD to occur during hypersensitive (HR) in response to TMV is attributed to VPEs (del Pozo and Lam 1998; Hatsugai et al. 2004). VPEs also play an important role in other types of plant PCD such as embryogenesis (Hara-Nishimura et al. 2005), seed development (Nakaune et al. 2005), and leaf senescence (Kinoshita et al. 1999). In Arabidopsis, a total of 4 VPEs have been isolated and divided into two types (Kinoshita 
et al. 1995a, $b$; Nakaune et al. 2005; Yamada et al. 2005). Seed type VPEs, delta-VPE and beta-VPE, are mostly expressed in seeds. Vegetative type VPEs, alpha-VPE and gamma-VPE, are mainly expressed in vegetative tissue.

Lace plant (Aponogeton madagascariensis) is a submerged aquatic monocot which forms perforations in its leaves during normal development by way of PCD (Fig. 1; Gunawardena et al. 2004). Lace plant is one of the few plant species known to employ PCD during leaf morphogenesis. However, unlike in the other plant species such as Monstera obliqua, lace plant PCD regions are easily visible and occur at highly predictable locations (Figs. 1B-E). Lace plants can also be propagated in microbe-free conditions in magenta boxes for experimental purposes (Gunawardena et al. 2006; Fig. 1B). In addition, the lace plant is ideal for light microscopy due to its thin and transparent leaves. Lace plant leaf development has previously been divided into seven stages (Rantong et al. 2015). These stages are early preperforation, preperforation, early window, window, late window, mature and senescence stage. Visible signs of perforation-related PCD are observable during the early window, window and late window stages.

Ethylene plays a role in lace plant leaf development via PCD during perforation formation (Dauphinee et al. 2012; Rantong et al. 2015). In addition, a caspase-1 inhibitor (Ac-YVAD-CMK) is known to stops PCD and perforation formation in the lace plant, which provides indirect evidence for the involvement of VPEs in lace plant PCD during leaf morphogenesis (Lord et al. 2013). Due to the involvement of caspase-1 like activity and ethylene in lace plant PCD signaling, we investigated the interactions between VPEs and ethylene throughout perforation formation. Although links between ethylene and VPEs during PCD have been studied in the HR, to our knowledge no studies have investigated their relationship during developmentally regulated PCD.

The objective of this study was to isolate lace plant vegetative type VPEs and study their expression patterns and activity during developmentally regulated PCD and leaf development in the lace plant. Recently we showed that ethylene plays a role in lace plant PCD (Dauphinee et al. 2012; Rantong et al. 2015), therefore, we also investigated the 
effect ethylene biosynthesis inhibition on VPE transcript levels during leaf development via developmentally regulated PCD.

\section{Materials and Methods}

\section{Plant propagation}

Lace plants were propagated as described by Gunawardena et al. (2006), under sterile conditions, and in Magenta GA7 boxes. Plants were kept in $12 \mathrm{~h}$ light/12 h dark cycles. The light intensity was approximately $125 \mu \mathrm{mol} \mathrm{m} \mathrm{m}^{-2} \mathrm{~s}^{-1}$ and was provided through daylight simulating fluorescent bulbs (Philips, Daylight Deluxe, F40T12/DX, Markham, Ontario, Canada). The plants were maintained at $24^{\circ} \mathrm{C}$.

\section{RNA extraction and $c D N A$ Synthesis}

RNA was extracted from leaves sampled from seven different developmental stages described in Rantong et al. (2015). These leaf developmental stages are early preperforation, preperforation, early window, window, late window, mature) and senescence. Four RNA samples were collected from each leaf developmental stage. In total, 28 independent RNA samples were analyzed. Each RNA sample consisted of tissue from at least 3 leaves from different plants. RNA quality was determined through gel electrophoresis and spectrometry at $260 \mathrm{~nm}$. Synthesis of cDNA was performed as described in Rantong et al. (2015).

\section{PCR amplification of lace plant VPE cDNA}

Initial VPE fragments were amplified degenerate primers. The degenerate primers were designed using alignments of VPE sequences from different species, performed through CLC combined workbench (CLC Bio-Qiagen, Aarhus, Denmark). The sequences used in the alignment were from Arabidopsis thaliana (NM_128154), Ricinus communis (D17401), Vitis vinifera (XM_002276723), Populus trichocarpa (XM_006371798), Populus tomentosa (FJ461342), Malus hupehensis (FJ891065), Solanum tuberosum (NM_001288343), Zea mays (NM_001111649 and AJ131719), Hordeum vulgare (AM941114), Beta vulgaris (AJ309173), Nicotiana tabacum (AB075947 and AB075948), and Solanum tuberosum (EU605871). The forward and reverse degenerate primers used for amplification of the initial fragments of AmVPE1 are 5'- 
TGGCYRTGCTCATYGCCGGCTC-3' and 5'-ACCARGCTTTTDTAGGTYCC-3', respectively. Forward (5'-TGGGCYGTCCTSMTCGCCGG-3') and reverse (5'GGCATCCCAAGRACHCCAGGTCC-3') degenerate primers were used to amplify a fragment of AmVPE2. The PCR reactions consisted of $3.5 \mu \mathrm{l}$ of cDNA, $11.15 \mu 1$ nuclease free water, $1 \mu \mathrm{l}$ of $10 \mathrm{mM}$ dNTP mix, $1 \mu \mathrm{l}$ of $10 \mathrm{mM}$ forward and reverse primer, $2 \mu \mathrm{l}$ 10X Thermobuffer, and $0.35 \mu \mathrm{l}$ of $5 \mathrm{U} / \mu \mathrm{l}$ Taq DNA polymerase. PCR conditions consisted of initial denaturing at $94^{\circ} \mathrm{C}$ for 5 minutes, 40 cycles at $94^{\circ} \mathrm{C}$ for 30 seconds (denaturing), primer annealing at $48^{\circ} \mathrm{C}$ for 30 seconds, elongation at $72^{\circ} \mathrm{C}$ for 1 minute, and final elongation at $72^{\circ} \mathrm{C}$ for 10 minutes. After sequencing of the initial lace plant VPE fragments, 3'-RACE was used to isolate the rest of the 3 ' end, including 3 '-UTR using an abridged universal amplification primer (AUAP; 5'GTACTAGTCGACGCGTGGCC-3') and an anchored primer (AP; 5'GGCCACGCGTCGACTAGTACTTTTTTTTTTTTTTTTT-3').

\section{Sequence analysis}

Cloning and sequencing was performed as described in Rantong et al. (2015). BioEdit Sequence Alignment Editor (Carlsbad, Ottawa, Ontario, Canada) was used to trim low quality portions and vector sequences. It was also used to deduce the amino acid sequences from nucleotide data. Both nucleotide and amino acid sequences were then compared with National Center for Biotechnology Information (NCBI) nucleotide collection (blastn) and nonredundant protein (blastx) database sequences, respectively. ClustalW2 (Larkin et al., 2007) was used to calculate sequence percentage identities for both nucleotide and amino acid sequences.

\section{Phylogenetic analysis}

The lace plant VPE sequences were aligned with 34 known VPE sequences from other plant species using CLUSTALW (Thompson et al. 1997). The VPE sequences used for phylogenetic analysis were from both monocot and dicot species. MEGA version 6.06 was used to construct a single tree using the Neighbor-Joining method. A gap at the $5^{\prime}$ in lace plant sequences and the corresponding amino acids in all other sequences was removed prior to construction of the phylogenetic tree. Branch strength was calculated 
using 1000 replicates in a nonparametric bootstrap test. The rice putative asparaginespecific endopeptidase precursor (NP_910213) was used as an out-group.

\section{Analysis of VPE transcript levels throughout leaf development}

VPE transcript levels were measured in the seven different stages of lace plant leaf development. AmVPE1 and AmVPE2 transcripts were detected in cDNA from all leaf developmental stages. The primers used for quantitative PCR (QPCR) did not amplify any products from genomic DNA, but amplified expected-size products in cDNA samples. Actin was used as a reference gene. Transcript levels from four different RNA samples per leaf developmental stage (28 independent RNA samples in total) were analyzed. Transcript levels were determined through QPCR. The QPCR reactions were performed in a Rotor-Gene 3000 (Corbett Research, Sydney, Australia) using QuantiTect SYBR Green PCR Kit (Qiagen, Mississauga, Ontario, Canada), following the manufacturer's instructions. The forward and reverse primers used for amplifying AmVPE1 fragments are 5'-GCATTGTTAAGGAGCGGACA-3' and 5'TTGTACCCATAAACAAGGCAAT-3' respectively. Forward primer 5'-CCGAGTG GTTAAAGAACGAA-3' and reverse primer 5'-CTGAACCAATGTACAAGGCAAGT3' were used to amplify fragment of AmVPE2. Prior to QPCR, these primers were used in regular PCR to amplify fragments. The fragments were ligated into a pGEM-T vector, cloned, sequenced and verified to be the expected fragment. The QPCR conditions used consisted of $95^{\circ} \mathrm{C}$ for $15 \mathrm{~min}$ (initial denaturing), 40 cycles of $94^{\circ} \mathrm{C}$ for $20 \mathrm{~s}$ (denaturing), primer annealing at $60^{\circ} \mathrm{C}$ for $20 \mathrm{~s}$, and $72^{\circ} \mathrm{C}$ for $30 \mathrm{~s}$ (elongation). Product purity was determined by observing the melting temperature curve at the end of QPCR. A standard curve of copy number was generated from quantified target sequences for each gene. The standard curves were used to determine mRNA copy numbers as explained in Bustal et al. (2005). Absolute mRNA copy number of each VPE was divided by AmActin (KR779004.1) mRNA copy number to obtain a mean normalized expression value in each sample. Actin primers used for QPCR are 5'-TACGACAGGTATCGTGCTTG-3' and 5'-CAAGCACGATACCTGTCGTA-3'. 


\section{Analysis of VPE transcript levels between dying (PCD) and non-PCD (NPCD) cells}

To further examine the role of VPEs in lace plant PCD, transcript levels were determined in PCD and NPCD cells. A Zeiss PALM Laser Capture Microdissection and Imaging System (North York, Ontario, Canada) was used to separate PCD and NPCD cells. The cells were collected from early window and window stage leaves, in which the cells are easily visually distinguishable through color differences. NPCD cells have high amounts of anthocyanin and are pink. Most of the anthocyanin is lost in PCD cells (Figure 1D). Cells were collected from at least three different leaves per sample and a total of 8 different samples (four samples per cell type) were used for RNA extraction. A ReliaPrep RNA Cell Miniprep kit (Promega, Nepean, Ontario, Canada) was used for RNA extraction, following manufacturer's instructions. RNA was treated with DNase 1 prior to cDNA synthesis. A Protoscript M-MuLV First Strand cDNA Synthesis Kit (New England Biolabs, Pickering, Ontario, Canada) was used for cDNA synthesis.

\section{Labelling of leaf tissue with VPE activity probe JOPD1}

Labelling was performed using a protocol modified from Lu et al. (2015). Window stage lace plant leaves were dissected into sections of approximately $9 \mathrm{~mm}^{2}$. The labelling was performed in $300 \mu \mathrm{l}$ total volume containing distilled water and $0.5 \%$ silwett L77 (Shawnee Mission, Kansas, USA). For treatments, the leaf tissue was incubated in $4 \mu \mathrm{M}$ JOPD1 probe solution (kindly donated by Dr. Renier van der Hoorn, Max Planck Institute for Plant Breeding Research, 50829 Cologne, Germany) for $24 \mathrm{~h}$ at room temperature under constant shaking. In no-probe-controls, an equal volume of DMSO was added. JOPD1 is an activity-based BOPIDY tagged probe that targets VPEs. Details on the synthesis and mode of action of JOPD1 are provided in Lu et al. (2015) and Ashnest et al. (2015). In short, a permanent covalent bond is produced between VPEs and JOPD1 when the active VPEs catalyze the cleavage of the probe. This interaction produces fluorescence detectable through a confocal microscope. A Nikon C1 Confocal Imaging System with an Eclipse Ti inverted Microscope (Nikon, Mississauga, Ontario, Canada) was used to detect the fluorescence of the BOPIDY fluorescence tag (excitation $561 \mathrm{~nm} /$ emission 595/50 nm). For each experiment, there were 4 replicates and the experiment was repeated three times. 


\section{AVG treatment}

Plants were treated with $5 \mu \mathrm{mol} / \mathrm{L}$ AVG (Sigma Aldrich, St. Louis, Missouri, USA) as described in Dauphinee et al. (2012). Leaf tissue was harvested from plants three weeks post-treatment, and the plants had produced three-four new leaves. The leaves were separated into six stages of leaf development; early preperforation(EPP), preperforation (PP), early window (EW), window (W), late window (LW) and mature(M). Senescent stage leaves were not available in this experiment since the plants were harvested before any of the leaves reached senescence. RNA was extracted from leaves at each of the six developmental stages. At least three different leaves from different plants were used in each RNA sample. A minimum of four independent RNA samples per leaf developmental stage (24 independent samples in total) were used. cDNA synthesis and QPCR were also performed as described above.

\section{Statistical analysis}

GraphPad Prism version 5.00 (San Diego, California, USA) was used to analyze Quantitative PCR data. Relative abundance of gene transcripts is presented as mean \pm S.E.M. For leaf developmental stages, significant differences in the number of transcripts were determined through a general linear model of variance (ANOVA). Means of individual treatments were compared using a Tukey post-test, if the overall relationships were significant. An unpaired t-test was used for comparisons of relative transcript levels between PCD and NPCD cells. For the AVG experiment, a two-way ANOVA with no repeated measures, followed by Bonferroni post-test, was used to determine significant differences in transcript levels. Data was determined to be statistically significant if $P<$ 0.05 .

\section{Results}

\section{Lace plant VPES}

Two vegetative type lace plant VPEs, AmVPE1 (KR779002) and AmVPE2 (KR779003), were isolated. Their isolated fragments were 1436 and 1603 base pairs, respectively. The entire $3^{\prime}$ end of their cDNA was isolated, including the untranslated region. At the nucleotide level, $A m$ VPE1 and AmVPE2 fragments were $83.6 \%$ identical. They both translated into 437 amino acid fragments (Fig. 2A). At the amino acid level, they were 
$88.3 \%$ identical. They were both more identical to Arabidopsis vegetative type VPEs than to the seed type. AmVPE1 was $69 \%$ and $71 \%$ identical to Arabidopsis gamma and alpha-VPEs respectively. It was only 58 and $53 \%$ identical to the seed type Arabidopsis VPEs (beta and delta-VPE, respectively). AmVPE2 shareed $68 \%$ and $70 \%$ identity to Arabidopsis gamma and alpha-VPEs respectively, while it was only $60 \%$ and $52 \%$ identical to the Arabidopsis beta and delta-VPEs, respectively.

The domains and sites identified within AmVPE1 and 2 that are conserved in Arabidopsis vegetative VPEs include the mature protease domain, essential amino acids (Cys102, His191 and Cys241), N-glycosylation site (Asn360), and a C-terminal propeptide (Figure 2A). Most of these are also conserved in Arabidopsis seed-type VPEs, except His191, which is an essential amino acid, and is instead replaced by an Asn in delta-VPE. Also, less of the C-terminal propeptide region is conserved between lace plant VPEs and Arabidopsis seed-type VPEs, compared to vegetative type Arabidopsis VPEs (Fig. 2A).

Phylogenetic analysis comparing the amino acid sequence of $A m$ VPE1 and $A m$ VPE2 with 34 VPEs in other plant species, also revealed that they share more in common with the vegetative type VPEs than seed type VPEs (Fig. 2B). AmVPE1 and 2 also appear to be more related to the monocot (rice and maize) vegetative type VPEs than the dicot vegetative VPEs (Fig. 2B).

\section{AmVPE1 and AmVPE2 transcript expression levels in different stages of lace plant leaf development}

Transcript level results demonstrated that the lace plant VPE transcripts are differentially expressed during leaf development. AmVPE1 transcripts levels in leaves sampled at the preperforation stage were significantly higher than at all other stages of leaf development (Fig. 3A). This stage of leaf development is immediately prior to obvious visible signs of PCD and perforation formation. During the early window and window stage, the AmVPE1 transcript levels were approximately 2-foldlower than in preperforation. During the late stages of PCD, in late window stage, the AmVPE1 transcript levels declined to about 3-fold less than in the early window and window stages. In mature and senescence stage leaves, the AmVPE1 transcripts are at their lowest levels as compared to all the other stages of leaf development. AmVPE2 transcript levels were about 1.4-fold higher in 
window and late window stage leaves (in which rapid cell death was occurring) than in other stages (Fig. 3B). There were no significant differences in AmVPE2 transcript levels among all the other stages (early preperforation, preperforation, early window, mature and senescence) of leaf development. AmVPE2 transcript levels were approximately 1000-fold higher than AmVPE1 transcript levels. AmActin transcripts were constitutively expressed throughout leaf development (Fig. 3C).

\section{AmVPE1 and AmVPE1 transcript levels in PCD versus NPCD cells}

QPCR showed that PCD cells had significantly higher transcript levels of both lace plant VPEs than the NPCD cells (Figs. 4A and B). AmVPE1 transcript levels were about 3.2fold higher in PCD than in NPCD cells. The amount of AmVPE2 transcripts in PCD cells was more than double the amount in NPCD cells. AmVPE2 transcript levels appeared to be higher (1000-fold) than AmVPE1 transcript levels at the cell level as well. AmActin transcript levels were not significantly different between the two cell types (Fig. 4C).

\section{VPE activity in PCD compared to NPCD cells}

Probe-associated fluorescence (red) was observed within vacuoles, where VPEs are known to be active (Fig. 5). The activity-based probe is an inhibitor tagged with a reporter (BOPIDY fluorescent reporter) and reacts specifically with VPE active-site residues. The VPE activity and fluorescence was higher in PCD cells compared to NPCD cells. Dead cells (late PCD cells) did not display probe-associated fluorescence (Figs. 5E and F). No probe-associated fluorescence was detected in the negative controls (Fig. 5D).

\section{Effects of AVG treatment}

\section{Leaf Morphology}

Representative leaf layouts were assembled to highlight leaf morphological differences at the six stages of development and between treatments (Fig. 6). Early preperforation (EPP) stage leaves (Figs. 6A and B) had just emerged from a corm, were light green, tightly furled and had no signs of perforation formation and PCD. Preperforation (PP) leaves (Figs. 6A and B) were still furled, and also did not show obvious signs of perforation formation or PCD. At the early window (EW) stage, leaves in control plants started to show signs of perforation formation. The perforation sites started to become 
somewhat transparent as PCD cells in these leaves started to lose their red pigmentation (Fig. 6A, leaf EW). In the AVG treated plants, however, the signs of perforation formation were minimal or nonexistent in early window stage leaves (Fig. 6Bleaf EW). The leaves in both the AVG treated and control plants were about half-unfurled at this stage. During the window (W) stage in control plants, perforation formation had progressed and leaves were actively forming perforations (Fig. 6A). In the AVG treated plants however, most of the window stage leaves did not have any signs of perforation formation (Fig. 6B,). During the late window (LW) stage in control plants, holes had formed within the perforation sites and were continuously getting larger as more cells within the perforation sites were undergoing PCD and disintegrating (Fig. 6A). The late window stage leaves in AVG treated plants, lacked holes and or any signs of PCD (Fig. 6B). Mature (M) stage leaves were fully perforated within control plants (Fig. 6A), while in AVG treated plants they had few or no perforations (Fig. 6B). Leaves that were produced before treatment (Figs. 6A and B, leaf M1) looked similar and had approximately the same number of perforations.

\section{AmVPE1 transcript levels in AVG treated and control plants}

Amongst control plants, preperforation and early window stage leaves had the highest AmVPE 1 transcripts compared to all other stages of leaf development. (Fig. 7A). The $A m V P E 1$ transcript levels were at their lowest in late window and mature stages. Amongst AVG treated plants, AmVPE1 transcript levels were not significantly different in early preperforation, preperforation, early window and window stage leaves. However, they declined significantly during the late window and mature stages.

The AmVPE1 transcript levels were also compared between AVG and control plants throughout the 6 stages of leaf development. During preperforation and early window stages, control plants had 2 to 3-fold higher AmVPE1 transcript levels than AVG treated plants. There was no significant difference in AmVPE1 transcript levels between AVG treated and control plants in early preperforation, window, late window and mature stages. 
AmVPE2 transcript levels in AVG treated and control plants

Amongst control plants, AmVPE2 transcript levels were 1.3 to 2-fold higher during the late window stage than all the other stages of leaf development (Fig. 7B). There were no significant differences in transcript levels between early preperforation, preperforation, early window, window and mature stages. Amongst AVG treated plants, there were no significant differences in AmVPE2 transcript levels throughout leaf development.

There were no significant differences in AmVPE2 transcripts levels between AVG and control plants in all stages of leaf development except the late window stage, where control plants had 1.4-fold higher AmVPE2 transcript levels.

\section{AmActin transcript levels in AVG treated and control plants}

AmActin transcripts were constitutively expressed amongst both AVG and control plants (Fig. 7C. Also, in preperforation, window and late window stages, there were no significant differences in AmActin transcript levels between AVG treated and control plants. However, AmActin transcript levels were around 1.2-fold lower in AVG treated plants during early preperforation, early window and mature stages compared to the same developmental stages in control plants.

\section{Discussion}

\section{Lace plant VPE transcript levels during leaf development}

Percentage identity, phylogenetic and domain analysis suggest that the two lace plant VPEs isolated are vegetative type VPEs. The lace plant VPEs are also more evolutionarily similar to other monocot vegetative type VPEs than dicot vegetative VPEs. Transcript levels suggest that both lace plant VPEs may be involved in PCD during perforation formation in the lace plant. AmVPE1 appears to be involved in the early stages of PCD, before any obvious visible signs of cell degradation (in preperforation stage leaves). AmVPE2 appears to be involved during the later stages of PCD (in window and late window stage leaves), where cellular degradation signs are obvious. Its higher transcript levels during the stages where PCD is actively occurring suggest that AmVPE2 may be involved in the later execution stages of PCD during perforation formation. The higher $A m V P E 1$ transcript levels in preperforation stage leaves and higher AmVPE2 in 
transcript levels in the window stage are consistent with the high caspase- 1 activity levels reported during these stages of leaf development (Lord et al. 2011). Lord et al. (2011) showed that there is higher caspase-1 activity in preperforation and window stage leaves compared to mature stage leaves. VPEs are responsible for caspase-1 like (YVADase) activity in plants (Hatsugai et al. 2004; Rojo et al. 2004; Misas-Villamil et al. 2013). Taken together, the findings suggest that the observed transcriptional increases of VPEs in the preperforation and window stage leaves may also translate to increased proteolytic activity within these leaves.

In other plant species, VPEs are sometimes known to display increases in transcript levels prior to visible signs of PCD (Iakimova et al. 2013). In apple leaves inoculated with Erwinia amylovora, increases in VPE transcript levels are detected prior to any visible lesion-associated PCD and also after obvious signs of lesion formation (Iakimova et al. 2013). The early-expressed VPEs are thought to be involved in early invisible signs of PCD, signaling/regulation or execution of processes leading to obvious signs of PCD. They may also activate proteases, hydrolases, enzymes responsible for cell degradation and death. VPEs are thought to mediate the maturation of hydrolytic enzymes within the vacuole, which degrade the tonoplast and initiate a proteolytic executing-PCD cascade (Guicciardi et al. 2004; reviewed in Hatsugai et al. 2015). Tonoplast rupture is one of the hallmarks of PCD in the lace plant, and it marks the beginning of rapid cell deterioration (Wright et al. 2009).

Developmentally regulated PCD also occurs as part of leaf senescence. Therefore, it was expected that both AmVPE1 and AmVPE2 transcript levels would be significantly higher during the senescence stage compared to stages in which PCD is not occurring. However, AmVPE1 transcript levels were at their lowest of all leaf developmental stages while $A m V P E 2$ transcripts were not significantly higher than the other stages where PCD is not occurring (Fig. 3). Based on these expression patterns, AmVPE1 and AmVPE2 may not play a role in leaf senescence. However, leaf senescence happens over an extended time period and PCD happens at the end of senescence. The leaves selected were at a specific stage of senescence and both VPEs may be involved at other stages of leaf senescence. An increase in AmVPE1 transcript levels may have happened prior to the PCD signs, as 
observed during perforation formation and AmVPE2 could be involved during the later stages where PCD is more rampant. VPEs in other plant species play a role in tissue senescence (Kinoshita et al. 1999; De Michele et al. 2009; Hoeberichts et al. 2007). In Lilium longiflorum, VPEs do not seem to be involved in the early stages of flower senescence, but are involved in regulation during the final stages of flower senescence (Battelli et al. 2011). To determine whether both AmVPE1 and AmVPE2 play a role in lace plant leaf senescence, we have to track changes in their transcript levels throughout the process of leaf senescence, instead of a specific senescence stage.

AmVPE1 and AmVPE2 transcript levels were significantly higher in the dying cells (PCD cells) than the non-dying cells (NPCD cells; Fig. 4). Suggesting that they may both play a role during the execution of PCD. Generally, AmVPE2 appeared to have higher transcript levels in leaves than AmVPE1. Therefore, it seems to be the more dominant VPE in lace plant leaf tissue, and its transcript expression pattern suggests it plays a more significant role during execution of perforation formation-associated PCD in the lace plant

\section{VPE activity analysis through JOPD1}

Although the transcript level evidence is compelling, due to the potential posttranslational regulation of VPEs, we investigated the activity levels of the VPEs within the two cell types. VPE activity during lace plant PCD was detected using a VPE-activity based probe JOPD1. VPE activity is determined by fluorescent labeling, because it implies the availability and reactivity of VPE active sites. This activity is observed in the vacuoles where VPEs are thought to be active, especially in the PCD types that involve vacuolar rapture, such as the lace plant PCD. Lu et al. (2015) demonstrated that JOPD1 labels all types of VPEs in Arabidopsis. The higher VPE activity and fluorescence in PCD cells compared to NPCD cells (Fig. 5) provides more evidence for the involvement of VPEs and VPE activity in lace plant PCD during perforation formation, and more support for the possible central role of VPEs in mediating PCD involving tonoplast rupture. VPE activity probes have been used in leaf extracts and cell cultures before (Misas-Villami et al. 2013; Lu et al. 2015), but to our knowledge, this study is the first to demonstrate the use of VPE activity-based probes in intact tissue sections. 


\section{Effect of AVG treatment on AmVPE1 transcript expression}

It is thought that ethylene is upstream (within the regulation phase) of VPEs within the plant PCD cascade (reviewed in Rantong and Gunawardena 2015). Lace plant produces high amounts of ethylene during the window stage and inhibition of ethylene biosynthesis stops PCD and perforation formation (Dauphinee et al. 2012). Through our AVG treatment experiments, we showed that reduced ethylene production also correlates with reduced VPE transcript levels. In control plants, the increase in AmVPE1 levels occurs at the beginning of perforation formation and PCD (Figs. 3A and 6). Treatment of plants with AVG seems to prevent the increase in AmVPE1 transcript levels during the preperforation and early window stage (Fig. 7A). Therefore, inhibiting ethylene biosynthesis correlates with hindrance of the increases in AmVPE1 transcript levels during developmental stages where PCD and perforation formation usually occur. The lack of VPE increase results in lack of PCD and perforations. This increase in ethylene levels may be required to trigger increased VPE transcription and execution of PCD in a similar manner proposed by Iakimova et al. (2013).

\section{Effect of AVG treatment on AmVPE2 transcript expression}

In control plants, AmVPE2 transcript levels increase significantly during the late window stage (Figs. 3B and 7B). Late window is the stage of leaf development where PCD is vigorously occurring and cells are disintegrating to give rise to holes at perforation sites. This increase is not evident in AVG treated plants. Therefore, the limited ethylene production due to AVG treatment coincides with the lack of increase in AmVPE2 transcript level. Ethylene may also be involved in the signalling leading to the increase in transcriptional upregulation of $A m \mathrm{VPE} 2$. The interconnection between ethylene and VPEs is not only unique to the lace plant. Kinoshita et al. (1999) showed that during ripening, treating citrus fruits with ethylene increases VPE transcript levels. Treatment with ethylene also results in increases in VPE transcript levels during plant defense against microbes (Liu et al. 2005).

\section{AmActin transcript levels in AVG treated and control plants}

AmActin was constitutionally expressed in both AVG treated and control plants (Fig. 7C). However, during early preperforation, early window and mature stages control plants had 
higher transcript levels than AVG treated plants. Ethylene is involved in many other cellular processes unrelated to PCD and its limited production may be affecting other metabolic processes unrelated to PCD including the transcription of housekeeping genes like AmActin. However, the $5 \mu \mathrm{mol} / \mathrm{L}$ AVG did not result in any developmental defects within the leaves (except for lack of perforations) and didn't induce differential expression of AmActin transcripts among leaf developmental stages.

Natural substrates cleaved by each of the lace plant VPEs need to be determined and their role during PCD needs to be investigated. The natural substrates would provide insight into whether AmVPE1 is also involved during the signalling or regulation phase of PCD, since its transcript levels increase early. The ability to transform the lace plant would also be important in order to study the effects of changes in VPE expression through knockout or over-expression lines. The data presented in this study suggest that VPEs are associated with cellular degradation in lace plant PCD and also that ethylene is upstream of VPEs in the plant PCD cascade. Ethylene production also seems to affect the rate and patterns of VPE transcription during lace plant leaf development via PCD. Other components, such as transcription factors, which may interact with VPEs and ethylene within the PCD cascade need to be studied to provide much needed insight into how components within the cascade work together to orchestrate PCD.

\section{Acknowledgements}

The authors acknowledge the Natural Sciences and Engineering Research Council of Canada (NSERC, grant no. 45162) and the Canada Foundation for Innovation (CFI, grant no. 14831) for providing funding to AHLAN.G. We also thank the Botswana government and Botswana International University of Science and Technology (BIUST) for providing Graduate scholarship funding to G.R. The authors also thank Dr. Julie Kang (University of Northern Iowa, USA) and Adrian Dauphinee (Dalhousie University) for critically reviewing this manuscript. We thank Dr. Renier van der Hoorn (Department of Plant Sciences, University of Oxford, UK)) for providing the VPE activity-based probe.

\section{Author contribution}


Gaolathe Rantong carried out all of the experiments, wrote the first manuscript and made final manuscript revisions. Arunika Gunawardena conceived the study, participated in its design and coordination, and helped in manuscript revisions as well as supervised all experimental work.

\section{Figure legends}

\section{Fig. 1. The lace plant.}

The lace plant (A) is an aquatic monocot that forms perforations on its leaves through developmentally regulated PCD. It can be grown in sterile conditions in Magenta boxes (B). Early in development, lace plant leaves do not show any signs of perforation formation (C). Eventually cells at the center of a perforation site (PCD cells) undergo PCD, while cells 4-5 layers from the vascular tissue (NPCD cells) remain alive (D). Once the PCD cells have disintegrated, actual holes are formed or perforations result (E). Scale $\operatorname{bars}(A)=1.25 \mathrm{~cm}, \mathrm{~B}=1 \mathrm{~cm},(\mathrm{C}-\mathrm{E})=100 \mu \mathrm{m}, \mathrm{D}=125 \mu \mathrm{m}$ and $\mathrm{E}=150 \mu \mathrm{m}$

Fig. 2. Alignment and phylogenetic analysis of lace plant VPE amino acid fragments. A. Domains and essential amino acids such as the mature protease domain (blue), essential amino acids (Cys76, His165 and Cys215; red), N-glycosylation site (spring green) and the C-terminal propeptide (orange) were identified. Dots represent amino acid identity and dashes indicate gaps. At the end of each sequence, its percentage identity and similarity with either AmVPE1 or AmVPE2 are indicated. Accession numbers: AtVPE-gamma (BAA018924.1), AtVPE-alpha (BAA09614.2), AtVPE-beta (BAA09615.1) and AtVPE-delta (BAC65233.1). B. During phylogenetic analysis, the vegetative VPEs from the different species (including lace plant) formed their own clade (highlighted in orange) away from the seed type VPEs (blue). Bar represents the gap separation distance, and the bootstrap values (from a thousand replicates) are indicated above or below each node. Rice asparagine-specific endopeptidase (NP_910213) was used as an outgroup in the Neighbor-Joining tree. Accession numbers of each amino acid sequence are provided in parentheses. 
Fig. 3. Changes in $A m$ VPE1 (A), $A m$ VPE2 (B) and $A m$ Actin (C) transcript levels at different stages of leaf development. For each VPE gene at each developmental stage, transcript levels are normalized to the level of AmActin, and represent the mean $\pm \mathrm{SE}$ of $\geq 12$ independent samples. (A) AmVPE1 transcript levels were higher in preperforation stage leaves compared to all the other stages of leaf development. (B) AmVPE2 transcripts were higher in window and late window stages, compared to the other stages. (C) AmActin transcripts were constitutively expressed throughout leaf development. Similar statistical letters indicate no significant difference at $P>0.05$. Abbreviations include: early preperforation (EPP), preperforation (PP), early window (EW), window (W), late window (LW), mature (M) and senescence (S).

Fig. 4. Mean Normalized $A m V P E 1$ and $A m V P E 2$ Transcript Levels in Dying (PCD) Versus Cells not Undergoing PCD (NPCD Cells).

The PCD and NPCD cells were separated from early window and window stage leaves using a Zeiss PALM Laser Capture Microdissection and Imaging System. Both AmVPE1 and AmVPE2 had higher transcript levels in PCD than NPCD cells. AmActin transcript levels were not significantly different between PCD and NPCD cells. Means with the same letters are not significantly different $(P>0.05)$. Bars represent $\mathrm{SE}(n \geq 8)$.

\section{Fig. 5. VPE activity analysis in PCD and NPCD cells.}

VPE activity was detected through an activity-based probe AMS-101. No probeassociated fluorescence was observed in the control (D). In window (B, E and $\mathbf{H})$ and late window (C, F and I) stage leaves, more fluorescence and VPE activity was detected in PCD cells than in NPCD cells ( $\mathbf{E}$ and $\mathbf{F}$ ). Dead cells at the centre of the perforation sites did not display any VPE activity. The experiment was repeated three times using 4 replicates in each experiment. A-C $=$ Bright field, $\mathbf{D}-\mathbf{F}=$ Fluorescence and $\mathbf{G}-\mathbf{I}=$ Overlay. Scale bars $=70 \mu \mathrm{m}$.

Fig. 6. Morphology of AVG treated lace plant compared to control plants. 
A leaf layout representing the different developmental stage leaves from control and AVG treated plant ( $\mathbf{A}$ and $\mathbf{B}$, respectively) was assembled to highlight the differences in perforation numbers between control and AVG treated plants. Control plants had the normal morphology with perforated leaves, while in AVG treated plants most of the leaves produced after treatment lacked perforations. The experiment was repeated four times using ten replicates in each treatment. The leaf developmental stages were early preperforation (EPP, preperforation (PP, early window $(\mathrm{EW})$, window (W, late window (LW) and mature (M). The M1 leaves developed before treatment. Bars $=1.8 \mathrm{~cm}$

\section{Fig. 7. Quantification of AmVPE1, AmVPE1 and AmActin transcripts through QPCR.}

Mean normalized $A m V P E$ transcript levels were determined in leaves at different stages of leaf development, in both control and AVG treated plants. During the preperforation and early window stages, AVG treated plants had lower transcript levels than control plants. During the late window stage, control plants had significantly higher AmVPE2 transcript levels than AVG treated plants. For each VPE gene, transcript levels are normalized to the level of AmActin at that developmental stage, and represent the mean \pm SE of $\geq 12$ independent samples. AmActin was constitutively expressed throughout leaf development in control and AVG treated plants. However, control plants had higher AmActin transcript levels during early preperforation, early window and mature stages than AVG treated plants. Asterisks highlight developmental stages displaying significant differences $(P<0.05)$ between treatments. Early preperforation, $\mathrm{PP}=$ preperforation, $\mathrm{EW}$ = early window, $\mathrm{W}=$ window, $\mathrm{LW}=$ late window and $\mathrm{M}=$ mature

\section{References}

Adrain, C., and Martin, S. J. 2001. The mitochondrial apoptosome: A killer unleashed by the cytochrome seas. Trends Biochem. Sci. 26:390-397. 
Albertini, A., Bauer, H., Cominelli, E., Galbiati, M., and Simeoni, F. 2014. Involvement of the vacuolar processing enzyme $\gamma \mathrm{VPE}$ in response of Arabidopsis thaliana to water stress. Biol. Plant. 58:531-538.

Alonso, J.M., and Granell, A. 1995. A putative vacuolar processing protease is regulated by ethylene and also during fruit ripening in Citrus fruit. Plant Physiol. 109:541-547.

Apelbaum, A., and Yang, S.F. 1981. Biosynthesis of stress ethylene induced by water deficit. Plant Physiol. 68:594-596.

Ashnest, A.R., Hyunh, D.L., Dragwidge, J.M., Ford, B.A., and Gendal, A.R. 2015. Arabidopsis intracellular NHX-type sodium-proton antiporters are required for seed storage protein processing. Plant and Cell Physiol. 56(11):2220-2233.

Battelli, R., Lombardi, L., Rogers, H.J., Picciarelli, P., Lorenzi, R., and Ceccarelli, N. 2011. Changes in ultrastructure, protease and caspase-like activities during flower senescence in Lilium longiflorum. Plant Sci. 180:716-725.

Bonneau, L., Ge, Y., Drury, G.E., and Gallois, P. 2008. What happened to plant caspases? J. Exp. Bot. 59:491-9.

Bozhkov, P.V., Filonova, L.H, Suarez, M.F., Helmersson, A., Smertenko, A.P., Zhivotovsky, B., and von Arnold, S. 2004. VEIDase is a principal caspase-like activity involved in plant programmed cell death and essential for embryonic pattern formation. Cell Death Differ. 11:175-82.

Bozhkov, P.V., Suarez, M.F., Filonova, L.H., Daniel, G., Zamyatnin, A.A, RodriguezNieto, S., Zhivotovsky, B., and Smertenko, A. 2005. Cysteine protease mcII-Pa executes programmed cell death during plant embryogenesis. Proc. Natl. Acad. Sci. U.S.A. 102:14463-8.

Cao, Y-R., Chen, S-Y., and Zhang, J-S. 2008. Ethylene signaling regulates salt stress 
response: An overview. Plant Signal Behav. 3:761-763.

Coffeen, W.C., and Wolpert, T. J. 2004. Purification and characterization of serine proteases that exhibit caspase-like activity and are associated with programmed cell death in Avena sativa. Plant Cell, 16:857-873.

Chichkova, N.V., Kim, S.H., Titova, E.S., Kalkum, M., Morozov, V.S., Rubtsov, Y.P., Kalinina, N.O., Taliansky, M.E., and Vartapetian, A.B. 2004. A plant caspase-like protease activated during the hypersensitive response. Plant Cell, 16:157-171.

Chichkova, N.V., Shaw, J., Galiullina, R.A., Drury, G.E., Tuzhikov, A.I., Kim, S.H., Kalkum, M., Hong, T.B., Gorshkova, E.N., Torrance L., Vartapetian, A.B., and Taliansky, M. Phytaspase, a relocalisable cell death promoting plant protease with caspase specificity. EMBO J. 29:1149-61.

Chichkova, N.V., Tuzhikov, A.I., Taliansky, M., and Vartapetian, A.B. 2012. Plant phytaspases and animal caspases: structurally unrelated death proteases with a common role and specificity. Physiol. Plant. 145:77-84.

Cohen, G.M. 1997. Caspases: the executioners of apoptosis. Biochem. J. 326 (1):1-16. Cravatt, B.F., Wright, A.T., and Kozarich, J.W. 2008. Activity-based protein profiling: from enzyme chemistry to proteomic chemistry. Annu. Rev. Biochem. 77:383-414.

Crawford, E.D., and Wells, J.A. 2011. Caspase substrates and cellular remodeling. Annu. Rev. Biochem. 80:1055-87.

Dauphinee, A.N., Wright, H., Rantong, G., and Gunawardena, A.H.L.A.N. 2012. The involvement of ethylene in programmed cell death and climacteric-like behaviour during the remodelling of lace plant (Aponogeton madagascariensis) leaves. Botany, 90:12371244. 
De Michele, R., Formentin, E., and Lo Schiavo, F. 2009. Legume leaf senescence. Plant Signal Behav. 4:319-320.

Del Pozo, O., and Lam, E. 2003. Expression of the baculovirus p35 protein in tobacco affects cell death progression and compromises $\mathrm{N}$ gene-mediated disease resistance response to tobacco mosaic virus. Mol. Plant Microbe Interact. 16:485-94.

Deng, M., Bian, H., Xie, Y., Kim, Y., Wang, W., Lin, E., Zeng, Z., Guo, F., Pan, J., Han, N., Wang, J., Qian, Q., and Zhu, M. 2011. Bcl-2 suppresses hydrogen peroxide-induced programmed cell death via OsVPE2 and OsVPE3, but not via OsVPE1 and OsVPE4, in rice. FEBS J. 278:4797-810.

Dodson, G., and Wlodawer, A. 1998. Catalytic triads and their relatives. Trends Biochem. Sci. 23:347-52.

Edgington, L.E., Verdoes, M., and Bogyo, M. 2011. Functional imaging of proteases: recent advances in the design and application of substrate-based and activity-based probes. Curr. Opin. Chem. Biol. 15:799-805.

Elmore, S. 2007. Apoptosis: a review of programmed cell death. Toxicol. Pathol. 35:495516.

Fukuda, H. 2000. Programmed cell death of tracheary elements as a paradigm in plants. Plant Mol. Biol. 44:245-253.

Gallois, P. 2015. Programmed cell death regulation by plant proteases with caspase-like activity. In Plant programmed cell death. Edited by A.H.L.A.N. Gunawardena and P.F. McCabe. Springer, New York. pp. 191-202.

González, I.J., Desponds, C., Schaff, C., Mottram, J.C., and Fasel, N. 2007. Leishmania major metacaspase can replace yeast metacaspase in programmed cell death and has arginine-specific cysteine peptidase activity. Int. J. Parasitol. 37:161-72. 
Greenberg, J.T. 1996. Programmed cell death: a way of life for plants. Proc. Natl. Acad. Sci. U.S.A. 93: 12094-7.

Groover, A., and Jones, A.M. 1999. Tracheary element differentiation uses a novel mechanism coordinating programmed cell death and secondary cell wall synthesis. Plant Physiol. 119:375-384.

Gunawardena, A.H.L.A.N., Greenwood, J.S., and Dengler, N.G. 2004. PCD remodels lace plant leaf shape during development. Plant Cell, 16:60-73.

Gunawardena, A.H.L.A.N., Navachandrabala, C., Kane, M., and Dengler, N.G. 2006. Lace plant: a novel system for studying developmental programme cell death. In Floriculture, Ornamental and Plant Biotechnology. Edited by J.A. Teixeira da Silva. Global Science Books, Ltd., Middlesex, UK. pp. 157-162.

Gunawardena, A.H.L.A.N., Pearce, D.M., Jackson, M.B., Hawes, C.R., and Evans, D.E. 2001. Characterisation of programmed cell death during aerenchyma formation induced by ethylene or hypoxia in roots of maize (Zea mays L.). Planta, 212:205-214.

Hara-Nishimura, I., Hatsugai, N., Nakaune, S., Kuroyanagi, M., and Nishimura, M. 2005. Vacuolar processing enzyme: an executor of plant cell death. Curr. Opin. Plant Biol. 8:404-8.

Hatsugai, N., Kuroyanagi, M., Yamada, K., Meshi, T., Tsuda, S., Kondo, M., Nishimura, M., and Hara-Nishimura, I. 2004. A plant vacuolar protease, VPE, mediates virusinduced hypersensitive cell death. Science, 305:855-858.

Hiraiwa, N., Nishimura, M., and Hara-Nishimura, I. 1999. Vacuolar processing enzyme is self-catalytically activated by sequential removal of the $\mathrm{C}$-terminal and $\mathrm{N}$-terminal propeptides. FEBS Lett. 447:213-216.

Hoeberichts, F.A., Van Doorn, W.G., Vorst, O., Hall, R.D., and Van Wordragen, M.F. 
2007. Sucrose prevents up-regulation of senescence-associated genes in carnation petals. J. Exp. Bot. 58:2873-2885.

Iakimova, E.T., Sobiczewski, P., Michalczuk, L., and Mikici, A. 2013. Morphological and biochemical characterization of Erwinia amylovora-induced hypersensitive cell death in apple leaves. Plant Physiol. Biochem. 63:292-305.

Jing, H.C., Sturre, M.J., Hille, J., and Dijkwel, P.P. 2002. Arabidopsis onset of leaf death mutants identify a regulatory pathway controlling leaf senescence. Plant J. 32:51-63.

Kim, Y., Wang, M., Bai, Y., Zenga, Z., Guoa, F., Hana, N., Biana, H., Wanga, J., Panb, J., and Zhua, M. 2014. Bcl-2 suppresses activation of VPEs by inhibiting cytosolic $\mathrm{Ca}^{2+}$ level with elevated $\mathrm{K}^{+}$efflux in $\mathrm{NaCl}$-induced PCD in rice. Plant Physiol. Biochem. 80:168-175.

Kinoshita, T., Nishimura, M., and Hara-Nishimura, I. 1995a. Homologues of a vacuolar processing enzyme that are expressed in different organs in Arabidopsis thaliana. Plant Mol. Biol. 29:81-89.

Kinoshita, T., Nishimura, M., and Hara-Nishimura, I. 1995b. The sequence and expression of the gamma-VPE gene, one member of a family of three genes for vacuolar processing enzymes in Arabidopsis thaliana. Plant Cell Physiol. 36:1555-1562.

Kinoshita, T., Yamada, K., Hiraiwa, N., Kondo, M., Nishimura, M., and Hara-Nishimura, I. 1999. Vacuolar processing enzyme is up-regulated in the lytic vacuoles of vegetative tissues during senescence and under various stressed conditions. Plant J. 19:43-53.

Kumamaru, T., Uemura, Y., Takemoto, Y., Ogawa, M., and Satoh, H. 2002. Highresolution mapping of glup3 gene accumulating high amount of glutelin precursor. Rice Genetics Newsletter 19:62-63.

Lam, E. 2004. Controlled cell death, plant survival and development. Nat. Rev. Mol. Cell Biol. 5:305-315. 
Lemaire-Chamley, M., Petit, J., Raymond, P., and Chevalier, C. 1999. Isolation and characterization of a fruit specific cDNA clone for vacuolar processing enzyme from tomato. Plant Physiol. 121: 1054.

Lenochová, Z., Soukup, A., and Votrubová, O. 2009. Aerenchyma formation in maize roots. Biol. Plant, 53:263-270.

Liu, Y., Schiff, M., Czymmek, K., Tallóczy, Z., Levine, B., and Dinesh-Kumar, S.P. 2005. Autophagy regulates programmed cell death during the plant innate immune response. Cell, 121(4):567-577.

Lombardi, L., Ceccarelli, N., Picciarelli, P., and Lorenzi, R. 2007. Caspase-like proteases involvement in programmed cell death of Phaseolus coccineus suspensor. Plant Sci. 172:573-578.

Lord, C.E.N, Dauphinee, A.N., Watts, R.L., and Gunawardena, A.H.L.A.N. 2013. Unveiling interactions among mitochondria, caspase-like proteases, and the actin cytoskeleton during plant programmed cell death (PCD). PLoS ONE, 8.

Lord, C.E.N., and Gunawardena, A.H.L.A.N. 2011. Environmentally induced programmed cell death in leaf protoplasts of Aponogeton madagascariensis. Planta,.233:407-21.

Lu, H., Chandrasekar, B., Oeljeklaus, J., Misas-Villamil, J., Wang, Z., Shindo, T., Bogyo, M., Kaiser, M., and van der Hoorn, R.A.L . 2015. Subfamily-specific fluorescent probes for cys proteases display dynamic protease activities during seed germination. Plant Physiol. 168:1462-1475.

Misas-Villamil, J.C., Toenges, G., Kolodziejek, I., Sadaghiani, A.M., Kaschani, F., Colby, T., Bogyo, M., and van der Hoorn, R.A.L. 2013. Activity profiling of vacuolar processing enzymes reveals a role for VPE during oomycete infection. Plant J. 73:689700 . 
Mur, L.A.J., Lloyd, A.J., Cristescu, S.M., Harren, F.J.M., Hall, M.A., and Smith, A.R. 2009. Nitric oxide interacts with salicylate to regulate biphasic ethylene production during the hypersensitive response in Arabidopsis: a window into defense priming mechanisms? Plant Signal Behav. 4:610-3.

Nakaune, S., Yamada, K., Kondo, M., Kato, T., Tabata, S., Nishimura, M., and HaraNishimura, I. 2005. A vacuolar processing enzyme, $\delta \mathrm{VPE}$, is involved in seed coat formation at the early stage of seed development. Plant Cell, 17:876-887.

Nicholson, D.W. 1999. Caspase structure, proteolytic substrates, and function during apoptotic cell death. Cell Death Differ. 6:1028-1042.

Piszczek, E., and Gutman, W. 2007. Caspase-like proteases and their role in programmed cell death in plants. Acta Physiol. Plant, 29:391-398.

Rantong, G., Evans, R., and Gunawardena, A.H.L.A.N. 2015. Lace plant ethylene receptors, AmERS1a and AmERS1c, regulate ethylene-induced programmed cell death during leaf morphogenesis. Plant Mol. Biol. 89:215-227.

Rantong, G., and Gunawardena, A.H.L.A.N. 2015. Programmed cell death: genes involved in signaling, regulation, and execution in plants and animals. Botany, 210:193210.

Reape, T.J., and McCabe, P.F. 2008. Apoptotic-like programmed cell death in plants. New Phytol. 180:13-26.

Reid, M.S., and Wu, M. 1992. Ethylene and Flower Senescence. Plant Growth Regul. 11:37-43.

Rojo, E., Martı, R., Carter, C., Zouhar, J., Pan, S., Plotnikova, J., Jin, H., Paneque, M., Sa, J., Baker, B., Ausubel, F.M., and Raikhel, N.V. 2004. VPE $\gamma$ exhibits a caspase-like activity that contributes to defense against pathogens. Curr. Biol. 14:1897-1906. 
Sanmartín, M., Jaroszewski, L., Raikhel, N.V., and Rojo, E. 2005. Caspases. Regulating death since the origin of life. Plant Physiol. 137:841-847.

Schnable, P.S., Ware, D., Fulton, R.S., Stein, J.C., Wei, F., Pasternak, S., Liang, C., Zhang, J., Fulton, L., Graves, T.A., Minx, P., Reily, A.D., Courtney, L., Kruchowski, S.S., Tomlinson, C., Strong, C., Delehaunty, K., Fronick, C., Courtney, B., Rock, S.M., Belter, E., Du, F., Kim, K., Abbott, R.M., Cotton, M., Levy, A., Marchetto, P., Ochoa, K., Jackson, S.M., Gillam, B., Chen, W., Yan, L., Higginbotham, J., Cardenas, M., Waligorski, J., Applebaum, E., Phelps, L., Falcone, J., Kanchi, K., Thane, T., Scimone, A., Thane, N., Henke, J., Wang, T., Ruppert, J., Shah, N., Rotter, K., Hodges, J., Ingenthron, E., Cordes, M., Kohlberg, S., Sgro, J., Delgado, B., Mead, K., Chinwalla, A., Leonard, S., Crouse, K., Collura, K., Kudrna, D., Currie, J., He, R., Angelova, A., Rajasekar, S., Mueller, T., Lomeli, R., Scara, G., Ko, A., Delaney, K., Wissotski, M., Lopez, G., Campos, D., Braidotti, M., Ashley, E., Golser, W., Kim, H., Lee, S., Lin, J., Dujmic, Z., Kim, W., Talag, J., Zuccolo, A., Fan, C., Sebastian, A., Kramer, M., Spiegel, L., Nascimento, L., Zutavern, T., Miller, B., Ambroise, C., Muller, S., Spooner, W., Narechania, A., Ren, L., Wei, S., Kumari, S., Faga, B., Levy, M.J., McMahan, L., Van Buren, P., Vaughn, M.W., Ying, K., Yeh, C.T., Emrich, S.J., Jia, Y., Kalyanaraman, A., Hsia, A.P., Barbazuk, W.B., Baucom, R.S., Brutnell, T.P., Carpita, N.C., Chaparro, C., Chia, J.M., Deragon, J.M., Estill, J.C., Fu, Y., Jeddeloh, J.A., Han, Y., Lee, H., Li, P., Lisch, D.R., Liu, S., Liu, Z., Nagel, D.H., McCann, M.C., SanMiguel, P., Myers, A.M., Nettleton, D., Nguyen, J., Penning, B.W., Ponnala, L., Schneider, K.L., Schwartz, D.C., Sharma, A., Soderlund, C., Springer, N.M., Sun, Q., Wang, H., Waterman, M., Westerman, R., Wolfgruber, T.K., Yang, L., Yu, Y., Zhang, L., Zhou, S., Zhu, Q., Bennetzen, J.L., Dawe, R.K., Jiang, J., Jiang, N., Presting, G.G., Wessler, S.R., Aluru, S., Martienssen, R.A., Clifton, S.W., McCombie, W.R., Wing, R.A., and Wilson, R.K. 2009. The B73 maize genome: complexity, diversity, and dynamics. Science, 326:1112-1115.

Senatore, A., Trobacher, C.P., and Greenwood, J.S. 2009. Ricinosomes predict programmed cell death leading to anther dehiscence in tomato. Plant Physiol. 149:775790. 
Shimada, T., Hiraiwa, N., Nishimura, M., and Hara-Nishimura, I. 1994. Vacuolar processing enzyme of soybean that converts proproteins to the corresponding mature forms. Plant Cell Physiol. 35:713-718.

Shishkova, S., and Dubrovsky, J.G. 2005. Developmental programmed cell death in primary roots of Sonoran Desert Cactaceae. Am. J. Bot. 92:1590-1594.

Tripathi, L.P., and Sowdhamini, R. 2006. Cross genome comparisons of serine proteases in Arabidopsis and rice. BMC Genomics, 7:200.

Tsiatsiani, L., Van Breusegem, F., Gallois, P., Zavialov, A., Lam, E., and Bozhkov, P.V. 2011. Metacaspases. Cell Death Differ. 18:1279-88.

Uren, A.G., O’Rourke, K., Aravind, L.A., Pisabarro, M.T., Seshagiri, S., Koonin, E.V., and Dixit, V.M. 2000. Identification of paracaspases and metacaspases: two ancient families of caspase-like proteins, one of which plays a key role in MALT lymphoma. Mol. Cell. 6:961-7.

Vartapetian, A.B., Tuzhikov, A.I., Chichkova, N.V., Taliansky, M., and Wolpert, T.J. 2011. A plant alternative to animal caspases: subtilisin-like proteases. Cell Death Differ. 18:1289-97.

Vercammen, D., van de Cotte, B., De Jaeger, G., Eeckhout, D., Casteels, P., Vandepoele, K., Vandenberghe, I., Van Beeumen, J., Inzé, D., and Van Breusegem, F. 2004. Type II metacaspases Atmc4 and Atmc9 of Arabidopsis thaliana cleave substrates after arginine and lysine. J. Biol. Chem. 279:45329-45336.

Wang, H., Li, J., Bostock, R.M., and Gilchrist, D.G. 1996. Apoptosis: a functional paradigm for programmed plant cell death induced by a host-selective phytotoxin and invoked during development. Plant Cell, 8:375-391.

Wang, H., Stier, G., Lin, J., Liu, G., Zhang, Z., Chang, Y., Reid, M.S, and Jiang, C. 2013. Transcriptome changes associated with delayed flower senescence on transgenic petunia 
by inducing expression of etr1-1, a mutant ethylene receptor. PLoS One, doi: 10.1371/journal.pone.0065800.

Wang, J., and Bayles, K.W. 2014. Programmed cell death in plants: lessons from bacteria? Trends Plant Sci. 18:133-139.

Wertman, J., Lord, C.E.N., Dauphinee, A.N., and Gunawardena, A.H. 2012. The pathway of cell dismantling during programmed cell death in lace plant (Aponogeton madagascariensis) leaves. BMC Plant Biol. 12:1-16.

Wilson, K.P., Black, J.A., Thomson, J.A., Kim, E.E., Griffith, J.P., Navia, M.A., Murcko, M.A., Chambers, S.P., Aldape, R.A., and Raybuck, S.A. 1994. Structure and mechanism of interleukin-1 beta converting enzyme. Nature, 370:270-275.

Woltering, E.J. 2004. Death proteases come alive. Trends Plant Sci. 9:469-472.

Wright, H., Van Doorn, W.G., and Gunawardena, A.H.L.A.N. 2009. In vivo study of developmental programmed cell death using the lace plant (Aponogeton madagascariensis; aponogetonaceae) leaf model system. Am. J. Bot. 96:865-876.

Yamada, K., Shimada, T., Nishimura, M., and Hara-Nishimura, I. 2005. A VPE family supporting various vacuolar functions in plants. Physiol. Plant, 123:369-375.

Young, T.E., Gallie, D.R, and DeMason, D.A. 1997. Ethylene-mediated programmed cell death during maize endosperm development of wild-type and shrunken2 genotypes. Plant Physiol. 115:737-751.

Zhang, D.S., Liang, W.Q., Yuan, Z., Li, N., Shi, J., Wang, J., Liu, Y.M., Yu, W.J., and Zhang, D.B. 2008. Tapetum degeneration retardation is critical for aliphatic metabolism and gene regulation during rice pollen development. Mol. Plant. 1:599-610. 
Zhang, J., Li, Q-F., Huang, W-W., Xu, X.Y., Zhang, X.L., Hui, M.X., Zhang, M.K., and Zhang, L.G. 2013. A vacuolar processing enzyme RsVPE1 gene of radish is involved in floral bud abortion under heat stress. Int. J. Mol. Sci. 14:13346-59. 


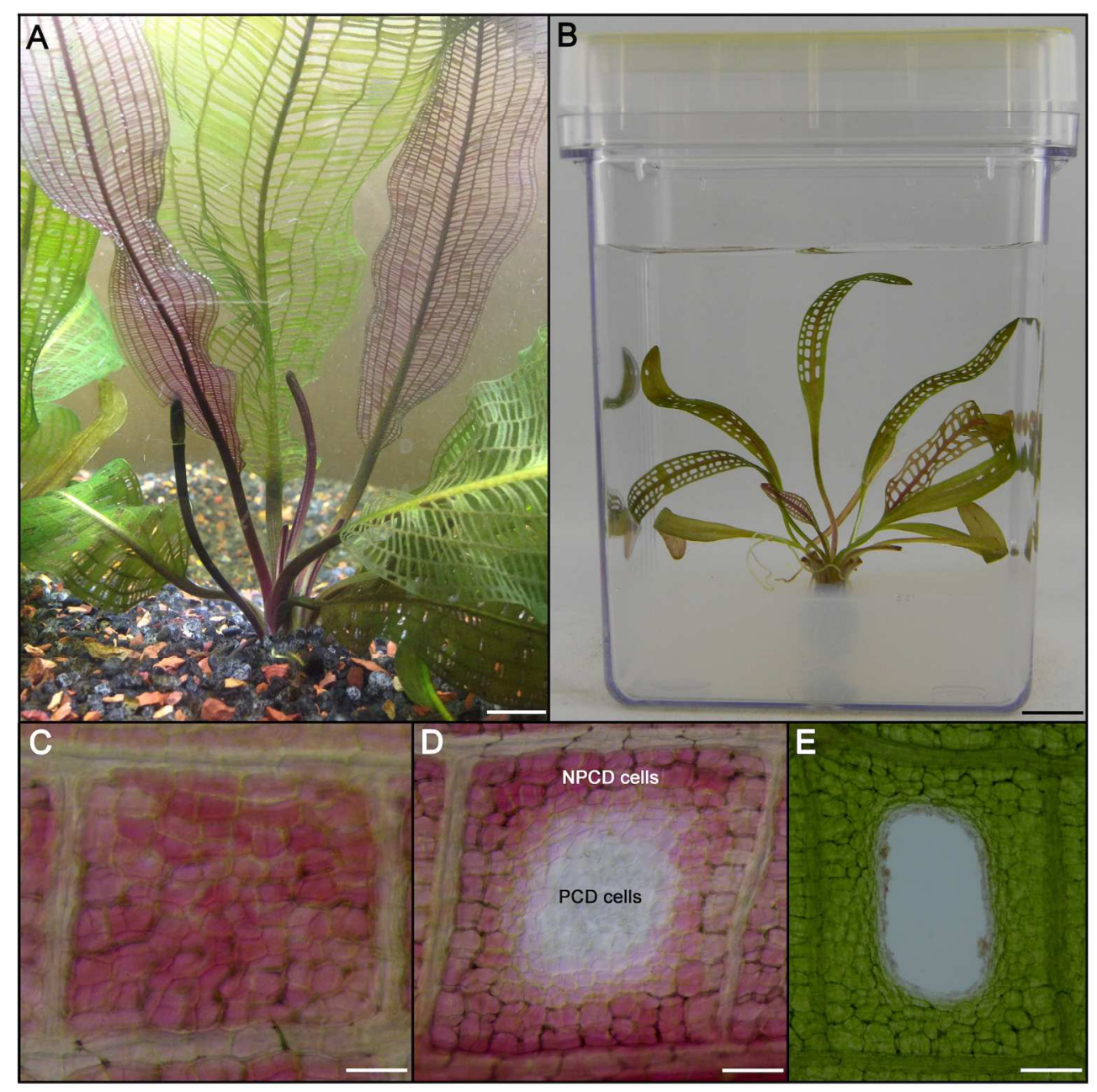

Fig. 1. The lace plant.

The lace plant $(A)$ is an aquatic monocot that forms perforations on its leaves through developmentally regulated PCD. It can be grown in sterile conditions in Magenta boxes (B). Early in development, lace plant leaves do not show any signs of perforation formation (C). Eventually cells at the center of a perforation site (PCD cells) undergo PCD, while cells 4-5 layers from the vascular tissue (NPCD cells) remain alive (D). Once the PCD cells have disintegrated, actual holes are formed or perforations result $(E)$. Scale bars $(A)=1.25$ $\mathrm{cm}, \mathrm{B}=1 \mathrm{~cm},(\mathrm{C}-\mathrm{E})=100 \mu \mathrm{m}, \mathrm{D}=125 \mu \mathrm{m}$ and $\mathrm{E}=150 \mu \mathrm{m}$ 


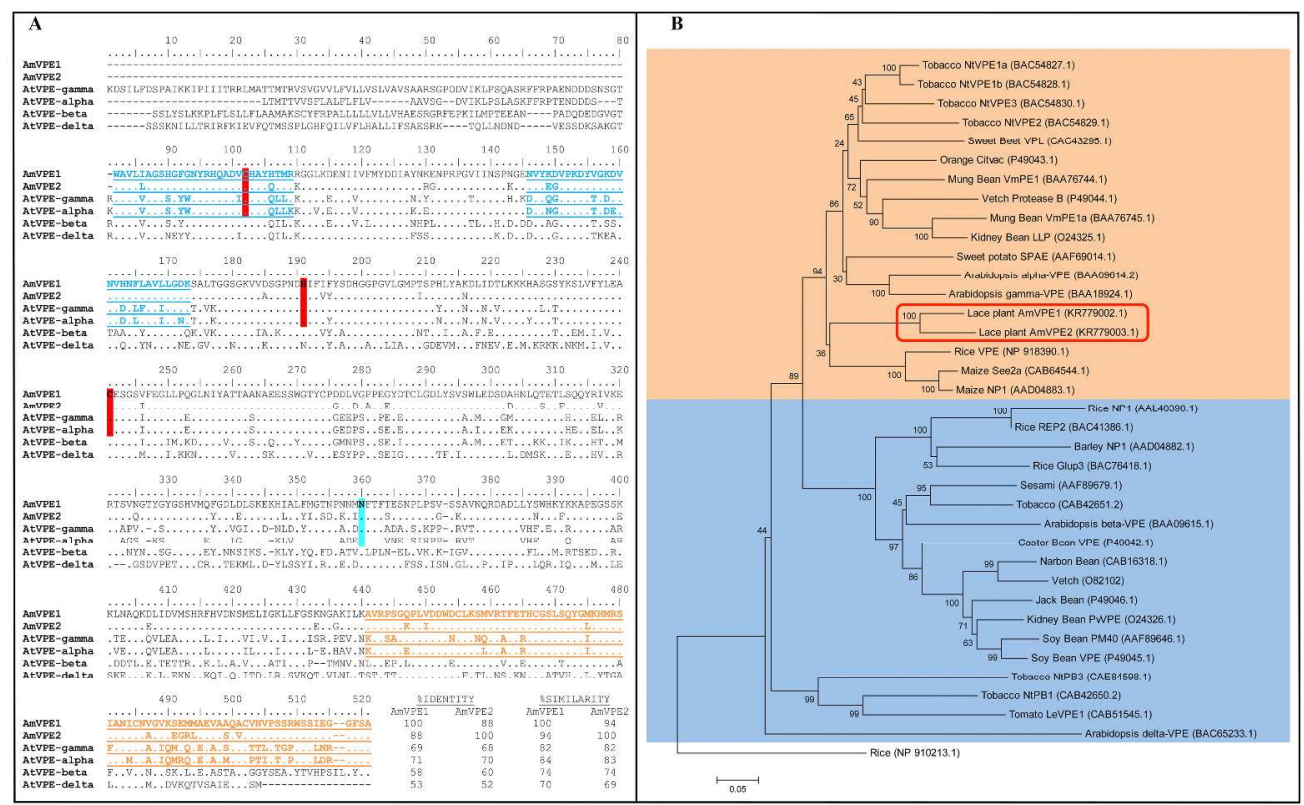

Fig. 2. Alignment and phylogenetic analysis of lace plant VPE amino acid fragments. A. Domains and essential amino acids such as the mature protease domain (blue), essential amino acids (Cys76, His165 and Cys215; red), N-glycosylation site (spring green) and the C-terminal propeptide (orange) were identified. Dots represent amino acid identity and dashes indicate gaps. At the end of each sequence, its percentage identity and similarity with either AmVPE1 or AmVPE2 are indicated. Accession numbers: AtVPE-gamma (BAA018924.1), AtVPE-alpha (BAA09614.2), AtVPE-beta (BAA09615.1) and AtVPE-delta (BAC65233.1). B. During phylogenetic analysis, the vegetative VPEs from the different species (including lace plant) formed their own clade (highlighted in orange) away from the seed type VPEs (blue). Bar represents the gap separation distance, and the bootstrap values (from a thousand replicates) are indicated above or below each node. Rice asparagine-specific endopeptidase (NP_910213) was used as an outgroup in the NeighborJoining tree. Accession numbers of each amino acid sequence are provided in parentheses.

$329 \times 203 \mathrm{~mm}(300 \times 300$ DPI $)$ 

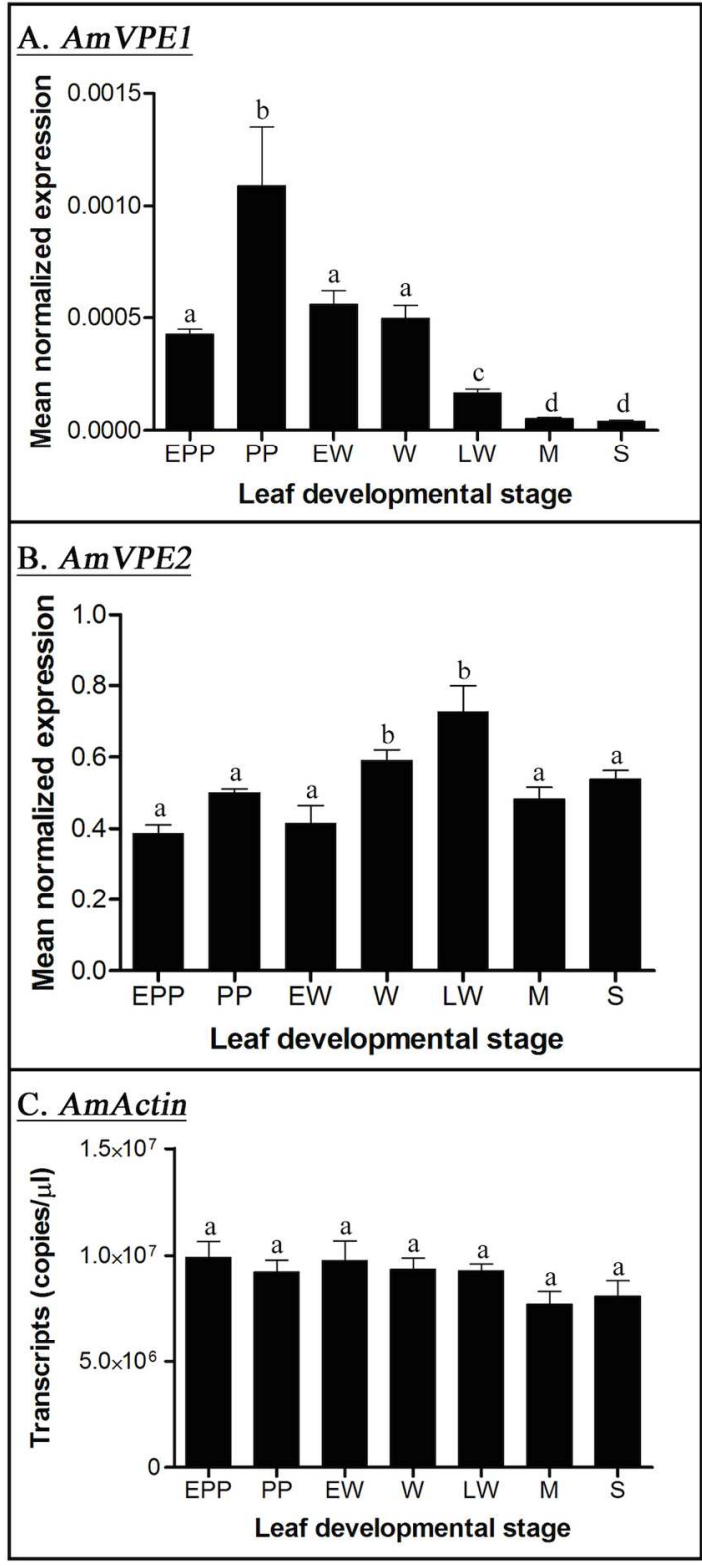

Fig. 3. Changes in AmVPE1 (A), AmVPE2 (B) and AmActin (C) transcript levels at different stages of leaf development. For each VPE gene at each developmental stage, transcript levels are normalized to the level of AmActin, and represent the mean \pm SE of $\geq 12$ independent samples. (A) AmVPE1 transcript levels were higher in preperforation stage leaves compared to all the other stages of leaf development. (B) AmVPE2 transcripts were higher in window and late window stages, compared to the other stages. (C) AmActin transcripts were constitutively expressed throughout leaf development. Similar statistical letters indicate no significant difference at $P>0.05$. Abbreviations include: early preperforation (EPP), preperforation (PP), early window (EW), window (W), late window (LW), mature (M) and senescence (S).

$$
83 \times 187 \mathrm{~mm}(300 \times 300 \text { DPI) }
$$




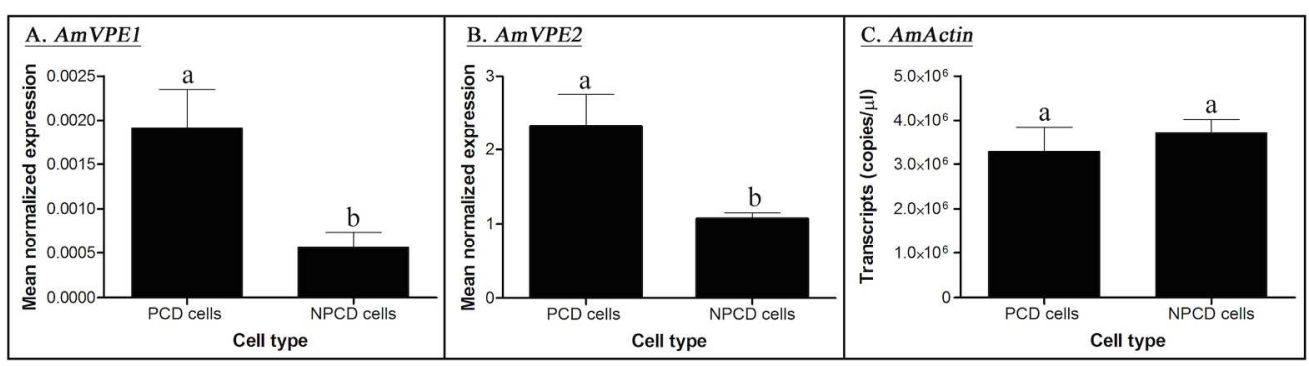

Fig. 4. Mean Normalized AmVPE1 and AmVPE2 Transcript Levels in Dying (PCD) Versus Cells not Undergoing PCD (NPCD Cells).

The PCD and NPCD cells were separated from early window and window stage leaves using a Zeiss PALM Laser Capture Microdissection and Imaging System. Both AmVPE1 and AmVPE2 had higher transcript levels in PCD than NPCD cells. AmActin transcript levels were not significantly different between PCD and NPCD cells. Means with the same letters are not significantly different $(P>0.05)$. Bars represent $S E(n \geq 8)$.

$172 \times 46 \mathrm{~mm}(300 \times 300 \mathrm{DPI})$ 


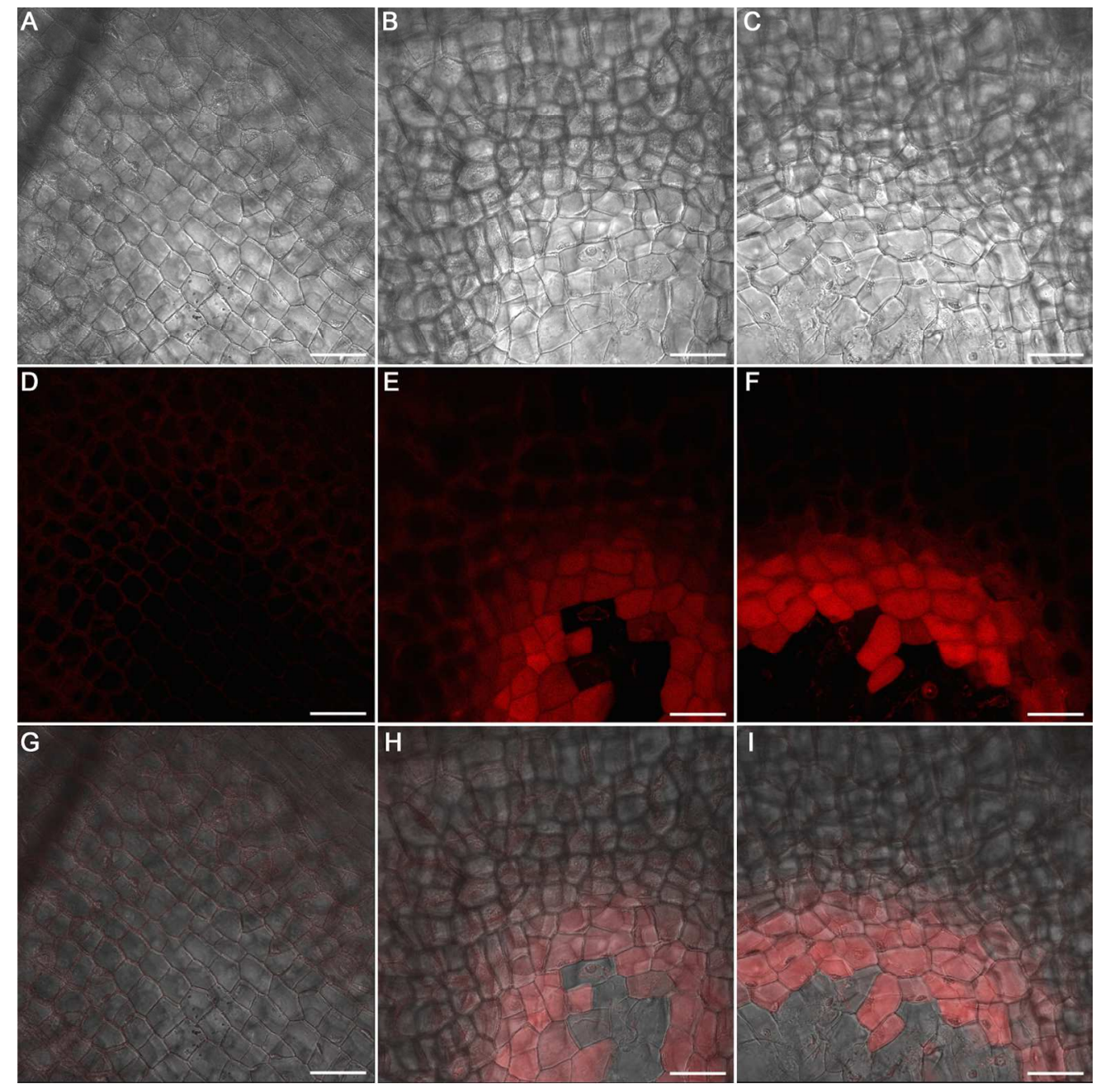

Fig. 5. VPE activity analysis in PCD and NPCD cells.

VPE activity was detected through an activity-based probe AMS-101. No probe-associated fluorescence was observed in the control (D). In window ( $B, E$ and $H$ ) and late window ( $C, F$ and I) stage leaves, more fluorescence and VPE activity was detected in PCD cells than in NPCD cells ( $E$ and F). Dead cells at the centre of the perforation sites did not display any VPE activity. The experiment was repeated three times using 4 replicates in each experiment. $A-C=$ Bright field, D-F = Fluorescence and $G-I=$ Overlay. Scale bars $=70 \mu \mathrm{m}$. 


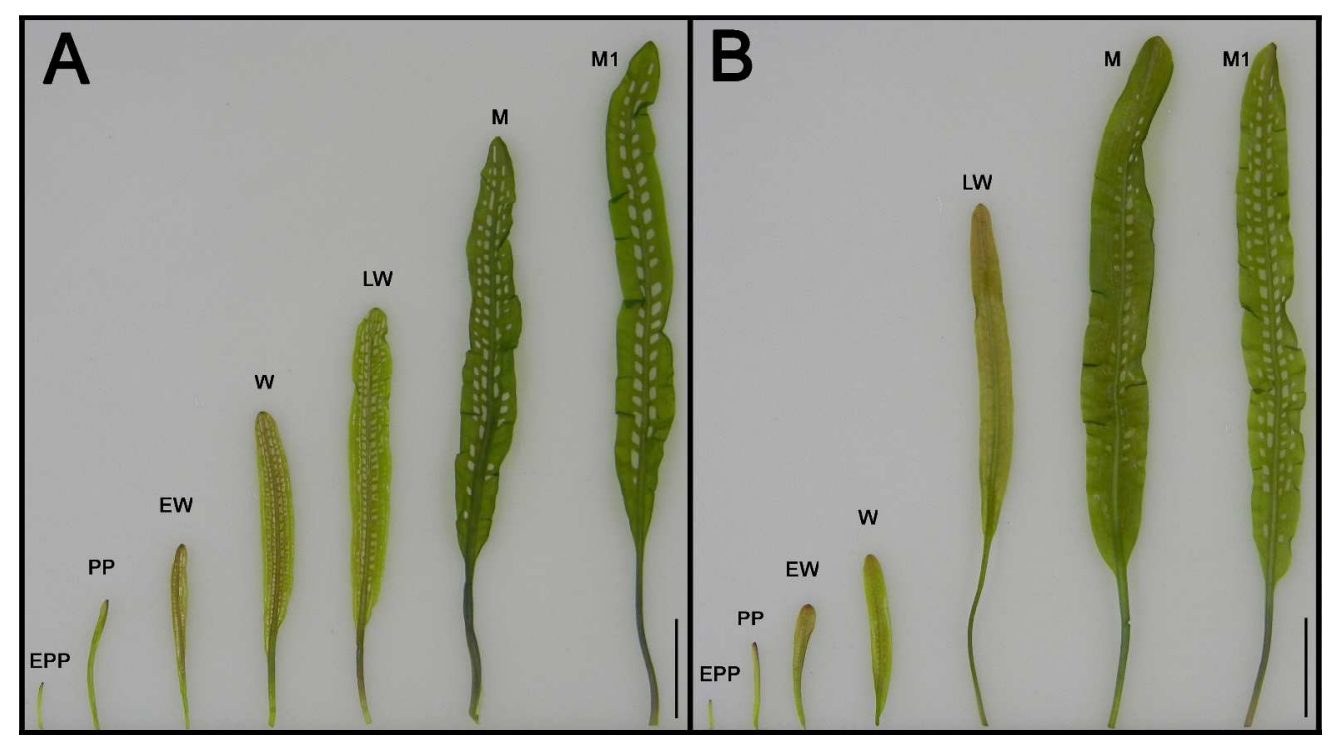

Fig. 6. Morphology of AVG treated lace plant compared to control plants.

A leaf layout representing the different developmental stage leaves from control and AVG treated plant ( $A$ and $B$, respectively) was assembled to highlight the differences in perforation numbers between control and AVG treated plants. Control plants had the normal morphology with perforated leaves, while in AVG treated plants most of the leaves produced after treatment lacked perforations.. The experiment was repeated four times using ten replicates in each treatment. The leaf developmental stages were early preperforation (EPP, preperforation (PP, early window (EW), window (W, late window (LW) and mature (M). The M1 leaves developed before treatment. Bars $=1.8 \mathrm{~cm}$

$321 \times 177 \mathrm{~mm}(300 \times 300 \mathrm{DPI})$ 

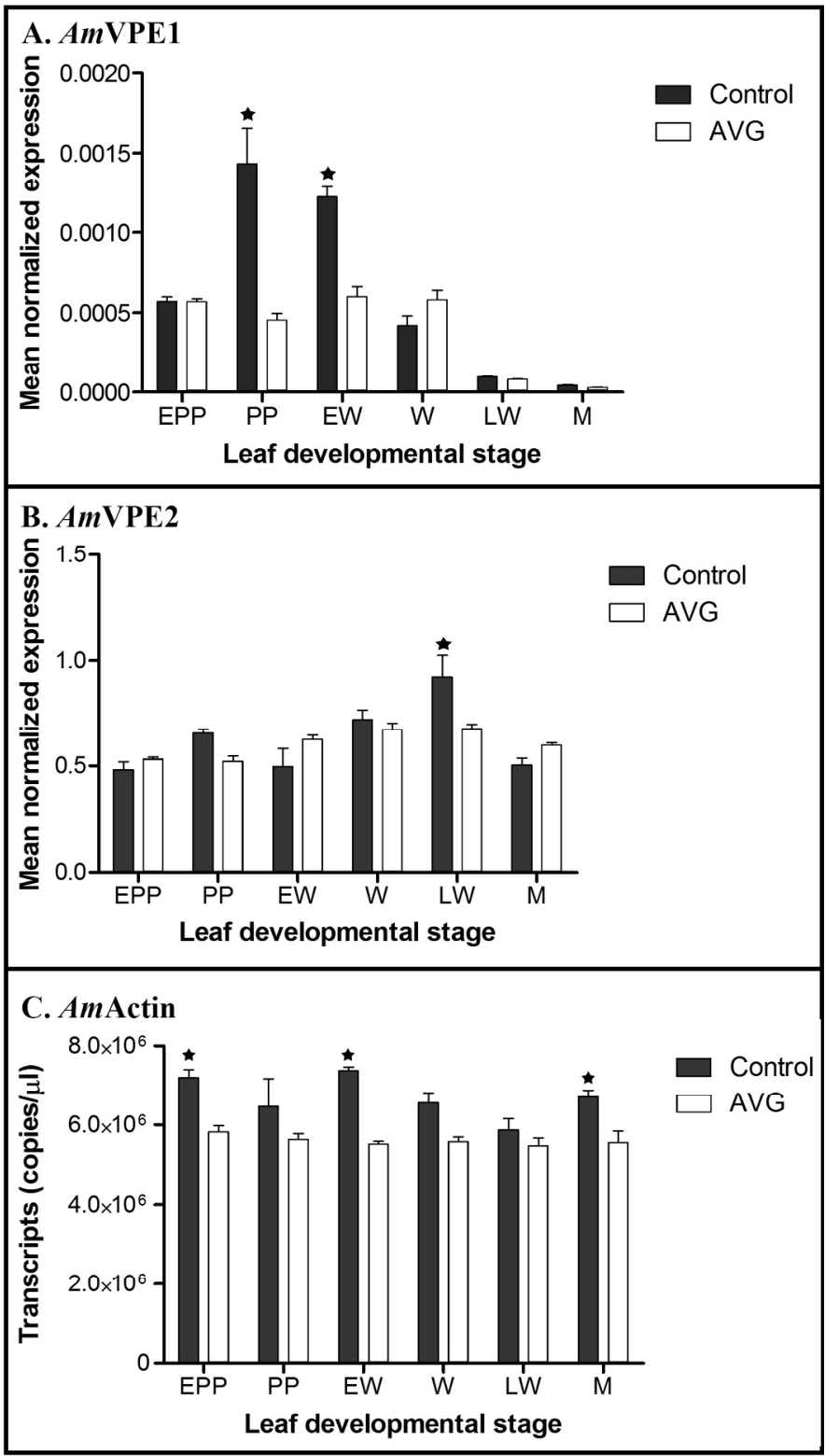

Fig. 7. Quantification of AmVPE1, AmVPE1 and AmActin transcripts through QPCR. $131 \times 231 \mathrm{~mm}(300 \times 300 \mathrm{DPI})$ 